\title{
Altair Lunar Lander Consumables Management
}

\author{
Tara Polsgrove ${ }^{1}$ \\ NASA Marshall Space Flight Center, Huntsville, Alabama, 35812 \\ Robert Button ${ }^{2}$ and Diane Linne ${ }^{3}$ \\ NASA Glenn Research Center, Cleveland, Ohio, 44135
}

The Altair lunar lander is scheduled to return humans to the moon in the year 2020. Keeping the crew of 4 and the vehicle functioning at their best while minimizing lander mass requires careful budgeting and management of consumables and cooperation with other constellation elements. Consumables discussed here include fluids, gasses, and energy. This paper presents the lander's missions and constraints as they relate to consumables and the design solutions that have been employed in recent Altair conceptual designs.

\section{Nomenclature}

$\begin{array}{ll}\text { AM } & =\text { Ascent Module } \\ \text { CSM } & =\text { Command and Service Module } \\ \text { D } & =\text { Duty Cycle } \\ \text { DAC } & =\text { Design Analysis Cycle } \\ \text { delta-V } & =\text { Delta Velocity } \\ \text { DM } & =\text { Descent Module } \\ \text { DRM } & =\text { Design Reference Mission } \\ \mathrm{E} & =\text { Energy } \\ \text { EDS } & =\text { Earth Departure Stage } \\ \text { EVA } & =\text { Extra-Vehicular Activity } \\ \text { LEO } & =\text { Low Earth Orbit } \\ \text { LLO } & =\text { Low Lunar Orbit } \\ \text { LM } & =\text { Lunar Module } \\ \text { LOC } & =\text { Loss of Crew } \\ \text { LOI } & =\text { Lunar Orbit Insertion } \\ \text { LOM } & =\text { Loss of Mission } \\ \text { LSS } & =\text { Lunar Surface Systems } \\ \text { MPS } & =\text { Main Propulsion System } \\ \text { P } & =\text { Equipment Power Level } \\ \mathrm{P}_{\text {ave }} & =\text { Average Power } \\ \text { PEL } & =\text { Powered Equipment List } \\ \text { PLSS } & =\text { Portable Life Support System } \\ t & =\text { Segment Duration } \\ \text { TLI } & =\text { Trans-Lunar Injection }\end{array}$

\section{Introduction}

WASA's new lunar lander vehicle - Altair - has been described as "Apollo on steroids" since the mission architecture is very similar to Apollo. This is not by accident. The physics of the lunar mission remain the same

\footnotetext{
${ }^{1}$ Aerospace Engineer, Advanced Concepts Office, ED 04, Tara.Polsgrove@nasa.gov.

${ }^{2}$ Chief, Diagnostics and Data Systems Branch, Power and Avionics Devision, MS 86-11.

${ }^{3}$ Senior Research Engineer, Power and In-Space Propulsion Division, MS 301-3, AIAA Associate Fellow.
} 
and an optimal engineering solution to the complex problem of moving mass between the gravity wells of Earth and the Moon should result in similar designs. However, there are important differences between the two vehicles that greatly affect what resources are available for consumption during the mission.

The lunar mission architecture requires the resource of two launch vehicles (Ares I and Ares V), a large Earth departure stage (EDS) booster, the Orion crew exploration vehicle, and the Altair lunar lander. Each component performs a necessary function in the manned lunar mission architecture. First, the Ares V launch vehicle lifts the EDS and Altair into low Earth orbit (LEO). The Ares I launch vehicle lifts Orion into LEO with the crew on-board. Orion and Altair/EDS rendezvous in LEO and the EDS pushes both Altair and Orion on a trajectory to the Moon. Once at the Moon, Altair is used to insert the vehicles into a low lunar orbit (LLO), land the crew on the lunar surface, provide a living environment for the crew for up to 7 days, and return them back to Orion in LLO. Once aboard Orion, the service module engine pushes the crew back to Earth, and the crew lands in the ocean using the Orion crew module. ${ }^{1}$

Altair consists of 2 major functional modules. The largest module is the Descent Module (DM). This contains the main propulsion system (MPS) necessary to perform the lunar orbit insertion (LOI) burn, lunar descent, and landing. The size of the DM is driven largely by the eight (8) massive propulsion tanks (4 liquid hydrogen tanks, 4 liquid oxygen tanks) required to fuel the engine. The much smaller module is called the Ascent Module (AM). The AM houses the crew during flight and on the surface, contains almost all the avionics, and a small ascent engine used to return the crew to Orion in low lunar orbit prior to returning to Earth. For long duration surface operations a removable Airlock is added for extra-vehicular operations and additional storage.

Altair is designed to take a crew of 4 astronauts to the lunar surface and support operations for up to 7 days. This far exceeds Apollo's mission of 2 astronauts on the surface for up to about 2.5 days. Besides the number of crew and duration of the mission, the major difference between Altair and Apollo -

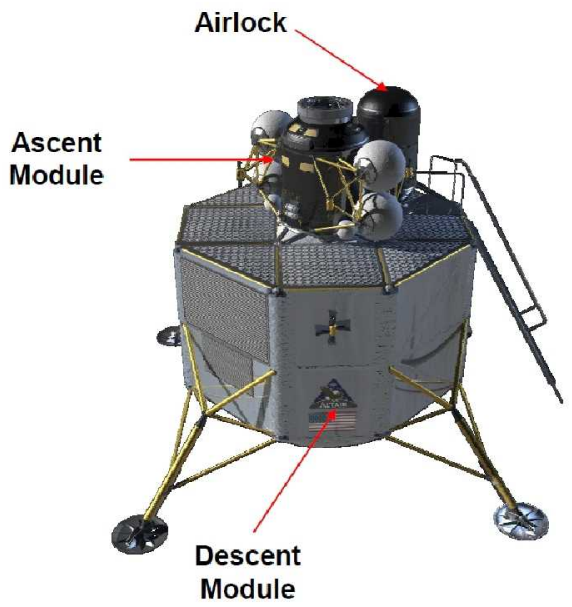

Figure 1. Altair Lunar Lander. and one that greatly impacts consumables - is that Altair was tasked by the mission architects with performing the lunar orbit insertion (LOI) burn. On Apollo the LOI burn was performed by the command and service module (CSM), however, the desire to optimize Orion for low-Earth orbit missions forced the LOI burn onto Altair. This large delta-V maneuver accounts for almost half of Altair's total delta- $\mathrm{V}$ requirements and greatly drives the size and design of the Altair main propulsion system (MPS). Since the delta-V requirements are so large for Altair, it was deemed early in the program that a hydrogen/oxygen fueled Altair MPS would be the most mass efficient means of performing the mission. As such, Altair lands with significant amounts of residual hydrogen and oxygen remaining in the large propulsion tanks, and the potential use of these residuals can positively affect the amount of consumables that Altair must carry.

\section{Design Reference Missions}

For this paper, three Altair missions are considered, Sortie, Outpost, and Cargo, each to a polar landing site. The Sortie uses all three lander elements, the DM, AM and Airlock, and stays for 7 days on the lunar surface. The Outpost mission is intended to be a crew rotation for an eventual lunar outpost. For this mission, only the DM and AM are required since the crew leaves the vehicle shortly after arriving on the lunar surface and does not return until just prior to ascent. The Cargo mission does not carry crew, so only the DM is needed. These missions are performed using a common DM. Requirements for a global sortie, or a lander that can go almost anywhere on the lunar surface, are still in flux, so that mission will not be discussed in this paper.

For the two crewed missions considered, three abort scenarios have been studied. A descent abort can be called if something goes wrong during the lander's descent to the lunar surface. In this scenario, the AM would separate from the DM and return the crew to lunar orbit and docking with Orion. Because of the non-optimal alignment of the Orion and Altair vehicles during an aborted descent, rendezvous can take several hours longer than in a nominal ascent. The second abort scenario is an early return. The crew can terminate the surface mission early if necessary, and return to Orion. The third scenario considered is the ascent abort. If something goes wrong during ascent, the 
vehicle will have enough supplies onboard to sustain the crew for 12 hours while Orion performs rendezvous maneuvers to meet the crew.

\section{Subsystem Design}

In studying the consumables required to complete each of Altair's missions it was found that several subsystems could be interconnected in a way that leads to lower initial lander mass. A discussion of power system design decisions which make this possible and some details on the propulsion, thermal and life support systems is given below as well as a brief description of propellant scavenging.

\section{A. Power Subsystem}

1. Power Source Selection

The original baseline design for the Apollo Lunar Module (LM) was to include fuel cell power plants in the descent stage to provide power during descent and surface operations, while the ascent module had batteries to provide power during a short ascent and rendezvous with the combined command and service module (CSM). However, because of the fuel cell complexity, the development costs, and schedule problems, the prime contractor was directed to convert to an all-battery power source design for the LM. ${ }^{2,3}$ The flight LMs were powered solely by silver-zinc (AgZn) batteries. This was possible due to the relatively short operational times (35-65 hours) and low average power consumption (1,100 Watts) of the Lunar Modules.

A trade study was performed during the first Altair design analysis cycle (DAC-1) in 2007 to determine the optimal power source (or sources) for the new vehicle. Inputs to the trade study were three design reference missions (DRMs), estimated average power requirements, and various power source options consisting of a mix of photovoltaic, battery, and fuel cell sources. Most attention was given to the Sortie mission as it was clearly the most challenging DRM for the power system. The Sortie mission is performed near the site of a future outpost at a southpole location where days-long eclipses are frequently encountered. Given these constraints it was quickly realized that an all-battery or solar array/battery power source would not be possible. After analyzing the three remaining power source options the most optimal solution was found to be a fuel cell on the Decent Module (DM) and a battery on the Ascent Module (AM), which is identical to the baseline Apollo design.

Once it was determined that a fuel cell power source would be optimal for Altair, it was quickly noted that the fuel cells would be able to use the same hydrogen and oxygen propellants that the DM main engine used, and that Altair would land on the lunar surface with significant propellant remaining in the large propulsion tanks. This remaining propellant would be a combination of margin that wasn't used during the mission (especially during landing) and residuals. Residuals are defined as propellant that cannot be used by the engine, either due to safety margins or propellant that simply cannot be delivered to the main engine in the proper condition. The current estimated residual propellant is estimated to be $3 \%$ of the maximum propellant load, which is $130 \mathrm{~kg}$ of hydrogen and $706 \mathrm{~kg}$ of oxygen. Using a conservative conversion factor of $2.2 \mathrm{~kW}$-hrs of energy from each $\mathrm{kg}$ of water produced by the fuel cell, this remaining propellant represents $1,746 \mathrm{~kW}$-hrs of electrical energy storage and $794 \mathrm{~kg}$ of water. Note that the amount of oxygen is the limiting factor as propellant is stored and burned in the engine in a 5.5:1 ratio of oxygen to hydrogen, whereas the fuel cell consumes the reactants in the stoichiometric ratio of 8:1. Considering that it has been estimated that it costs $\$ 50,000$ per pound to deliver mass to the lunar surface, this residual propellant that can be turned into energy and water using the Altair fuel cells is extremely valuable. ${ }^{4}$

\section{Power/Energy Requirements}

The only requirements levied on the electrical power system by the vehicle are generally just power quality specifications. There are almost never any power or energy requirements stated. This is because electrical power is an implied resource, and the designed power system must be able to generate and store enough energy to safely perform the mission and deliver power within specifications at all times. Therefore, in order for the power system to be properly designed, a detailed accounting of all the expected electrical loads must be performed even during early conceptual design activities. This information, along with detailed mission timelines and operational concepts, will determine the total energy generation and storage required.

To accomplish this accounting during the Altair design cycles a powered equipment list (PEL) was developed and maintained by the Power Subsystem. This PEL was focused on quantifying the total energy required of the vehicle, and determining an average power level for each mission segment. Initially a spreadsheet was developed that had each powered piece of equipment and its average power level in rows while each mission segment and its duration was noted in columns. Each subsystem lead was asked to populate the $\mathbf{M ~ x ~} \mathbf{N}$ matrix of data by estimating the duty cycle of their powered equipment in each mission segment. Knowing the equipment power level (P), duty cycle $(D)$, and segment duration $(t)$, the average power $\left(P_{\text {ave }}\right)$ and energy $(E)$ are easily calculated as: 


$$
\begin{gathered}
\mathrm{P}_{\mathrm{ave}}=\mathrm{P} * \mathrm{D} \\
\mathrm{E}=\mathrm{P}_{\mathrm{ave}} * \mathrm{t}(\text { or } \mathrm{P} * \mathrm{D} * \mathrm{t})
\end{gathered}
$$

While this method provides very good estimates for the energy generation and storage required to complete the mission, it is a poor method for estimating the instantaneous power (peak power) requirements for the sources and distribution system. As the Altair program matures a more rigorous database must be developed and maintained where high fidelity load profiles - including different modes of operation - can be tracked for each load. Figure 2 shows the current DAC3 Altair power timeline. This data has been used to size the energy storage capabilities (fuel cell reactants and batteries), thermal system designs, and the detailed consumables analysis presented below.

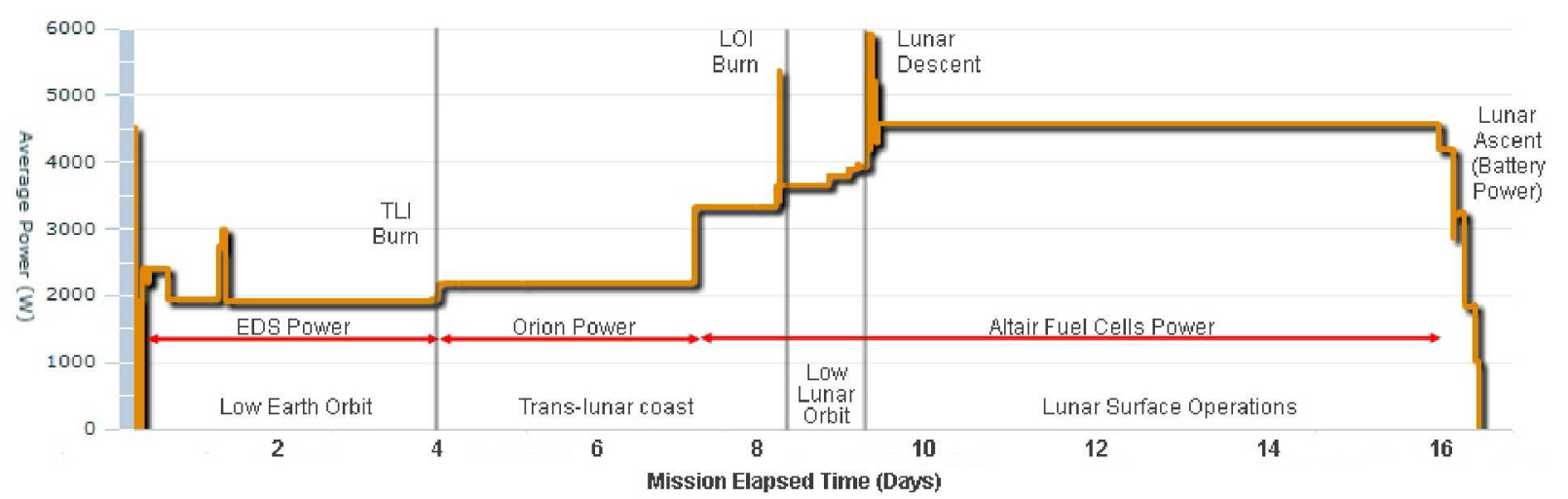

Figure 2. Altair Power Timeline (DAC3).

During the baseline Sortie mission Altair receives electrical power from four different energy sources. During Earth ascent, low-Earth orbit loiter, and the trans-lunar injection (TLI) burn Altair is in a quiescent state and receives all electrical power from the Earth Departure Stage (EDS), except for a short 3 hour window when Altair starts up the fuel cells to perform a vehicle checkout. Following the TLI burn Altair switches over to receiving electrical power from Orion which is now power rich due to a constant view of the sun and greatly diminished battery charging requirements. One day prior to the lunar orbit insertion (LOI) burn Altair re-starts its on-board fuel cells and is internally powered from that time forward. Until Altair lands on the surface, fuel cell reactants are drawn from small, dedicated tanks on the Descent Module (DM). Once on the surface, fuel cell reactants are drawn from residual fuel in the large DM propellant tanks for the remainder of the surface operations. ${ }^{5}$ Finally, the Ascent Module (AM) is powered solely by batteries when it returns the crew back to Orion in low-Lunar orbit (LLO). Figure 3 shows the trending of the Altair energy requirements for the four

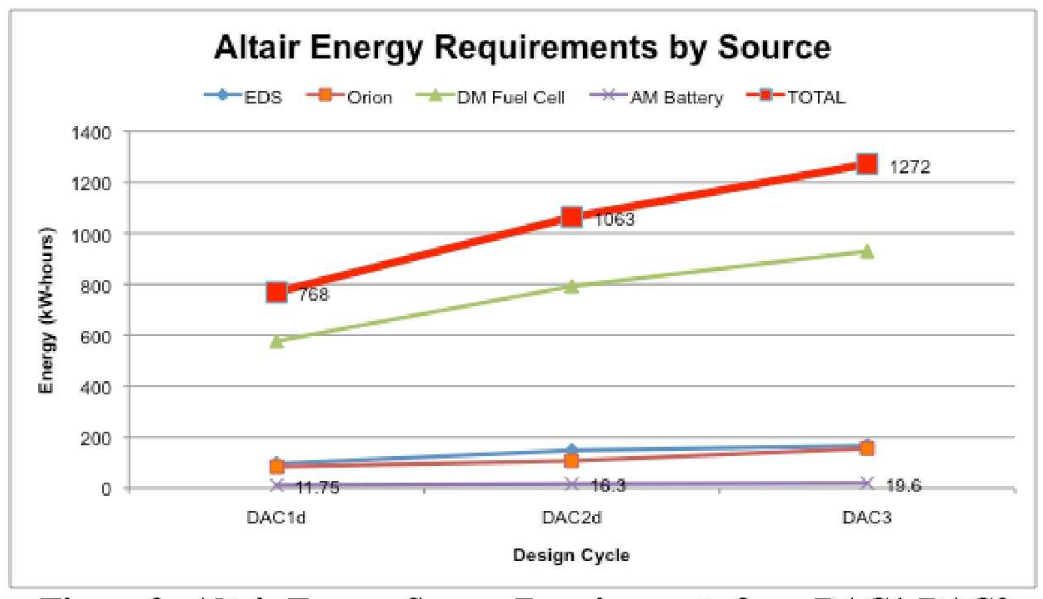

Figure 3. Altair Energy Source Requirements from DAC1-DAC3.

different sources over the three design cycles completed between June 2007 and April 2009. Whereas Apollo completed a 65 hour mission using only 70kW-hours of energy, current estimates for Altair show almost 1MWhours of energy requirements for the 225 hour Sortie mission.

While electronics technology has decreased exponentially in size and power since the days of Apollo, paradoxically, the average power consumption of Altair is expected to be much greater than that of Apollo, currently estimated to be about 4000 Watts average power consumption. This large increase in power requirements can be 
partially attributed to higher levels of automation, control, instrumentation, and redundancy, but is also greatly affected by physics which require more power to manage the environments for a larger vehicle, larger crew size, and different propulsion and propellant storage systems.

\section{B. Thermal Subsystem}

Altair thermal control is managed through use of surface coatings, heaters, radiators and sublimators. The primary method of heat rejection is through four radiator panels placed on the descent module. These reject heat for all three elements of the spacecraft when present, the descent module, ascent module and airlock. The Apollo LM relied entirely on sublimators for heat rejection. The sublimators for Apollo 17 consumed approximately $146 \mathrm{~kg}$ of water. ${ }^{6}$ On Altair the equivalent water consumption would be greater than $1,500 \mathrm{~kg}$. This difference is due to the longer mission duration, the higher heat loads from electrical power, and the addition of two astronauts. Design studies indicate that using radiators for Altair is more mass efficient than using sublimators alone. However, sublimators are still needed when the vehicle heat load cannot be entirely dissipated by the radiators. The combination of LLO beta angle and spacecraft attitude can result in periods of time where radiator panels become less effective. The Altair design team assumes a conservative zero beta angle orbit (the orbit plane is parallel with the sun vector) when designing thermal systems, which ensures that sufficient water is available for any orbit orientation. The three Altair DRMs considered in this paper each require sublimator use for portions of LLO loiter and lunar descent. During ascent, the sublimator is the primary method of heat rejection since radiators will be left behind on the descent module. Sublimator water is stored in the thermal tank, an external water tank located on the ascent module. The sublimators can also be fed from the potable water tank inside the ascent module. The water tanks can be loaded prior to Earth launch and refilled during the mission using fuel cell product.

\section{Life Support Subsystem}

The crew oxygen needs are supplied by five oxygen tanks and oxygen scavenged from the DM main propellant tanks once on the lunar surface. Two of the five tanks are high pressure tanks used to recharge the PLSS backpacks after each EVA. The other three work together to provide redundancy during the lander's descent to the Moon and subsequent ascent.

Crew water is stored in a single potable water tank in the ascent module. Drinking and hygiene water is extracted from this tank. Coolant water for each PLSS is extracted from the thermal tank, and replenished after each EVA. The primary source for crew water is the fuel cell water byproduct.

\section{Propulsion Subsystem}

The DM main propulsion system uses liquid hydrogen and oxygen stored in four large tanks each. The RCS and AM main propulsion use the storable propellants monomethylhydrazine and nitrogen tetroxide. Because of the commonality of hydrogen and oxygen with other systems, the residual propellants in the DM main tanks are of particular interest. At this early stage in the design the estimated amount of propellant that must remain in the tanks as residual may be between $2 \%-5 \%$ of the loaded tank volume. Altair designers are currently assuming $3 \%$ of the maximum propellant loading as residuals. A better estimate can be established once the tank geometry, internal structures and feed systems are more thoroughly designed and tested.

\section{E. Propellant Scavenging}

Several challenges must be addressed in order to enable the scavenging of the propellants from the descent module tanks for both fuel cell power and life support consumables. Because propellant residuals are by definition the propellant that is either difficult to get out of the tank due to design features (e.g., the location of the propellant outlet) or cannot be delivered to the engine at the proper quality, it is reasonable to assume that it will also be difficult to extract these residuals as cryogenic liquids for post-engine uses. Therefore, the analysis to date has focused on retrieving the residuals as gases from the tank ullage. Because helium is used to pressurize the propellant tanks, the first challenge then is to remove as much helium as possible from the ullage gas before sending to the fuel cells and life support systems. While this can be achieved through simple venting, the trick is to vent the helium while minimizing the loss of the precious propellant residual. There is also a trade involved between the pressure vented to and the minimum pressure required to operate the fuel cells. Preliminary analysis indicates that the concentration of helium in the hydrogen tank can be reduced to 3.2 mole percent (or volume percent) while maintaining 96 percent of the original hydrogen. The oxygen tanks present a greater challenge. While the helium concentration can be reduced to less than the 5 mole percent required by the life support systems, this would cause significant quantities of the liquid residual to be converted into vapor. This large vapor mass will result in greater oxygen losses later in the mission as it heats up from environmental loads and begins to over-pressurize the tank. A 
preliminary solution is to vent the oxygen tank from 95 to 43 mole percent ( 8.6 mass percent) helium, while losing less than 1 percent of the original oxygen. While initial tests indicate that the fuel cells should be able to handle these initially higher helium concentrations, more work is needed to further reduce the concentration before sending oxygen to the life support system (Ref. 5, Linne, et. al.).

Once sufficient helium is removed, the second challenge is to control the boil-off rate of the residual propellants to meet the consumable rate from the power and life support systems. For the oxygen, this may require adding heat to the tanks to increase the natural boil-off caused by the heat load from the environment alone. For the hydrogen, analysis has shown that approximately 3.5 days into the mission the tank pressure will reach the maximum operating pressure. At this point, excess hydrogen will either need to be vented or some means to capture the excess hydrogen will need to be developed to avoid over-pressurization. An additional complication is that the desired power draw is not constant, as discussed above, so the boil-off control also must consider the need to deliver gases at varied rates. It will be very challenging to speed up and slow down boil-off rates so some type of buffer volume may be required. The concepts being considered for propellant scavenging, challenges, and current analytical and experimental results are discussed in greater detail in Ref. 5 (Linne, et. al.).

There is a potential in the future for on-orbit propellant scavenging to maximize flexibility for dealing with failures in transit. If the mission were to be aborted prior to descent, the unused propellant could provide several days of power and water for the crew. The scavenging hardware would have to be different due to the difference in gravity and propellant conditions when the fluids are in orbit, but it may be worthwhile to study this option in the future.

\section{Consumables Analysis}

Integrated consumables analysis is required when multiple subsystems affect the same resource. This is true for several resources on the Altair lander. The Propulsion, Power, Life Support and Thermal systems each affect quantities of Oxygen, Hydrogen, and Water available for the mission.

\section{A. Subsystem Operational Assumptions}

Operational assumptions used in the consumables analysis including resource sharing assumptions between other constellation elements and Altair are given below.

\section{Power}

For crewed landers, electrical power resources are shared between the Earth Departure Stage (EDS), Orion, Lunar Surface Systems (LSS) and Altair. As stated earlier, the EDS provides power to Altair during launch up to EDS separation. Orion provides power to Altair beginning no earlier than 1 hour post TLI and ending $24 \mathrm{hrs}$ prior to LOI.

The Altair crewed landers power up fuel cells for a short period of time during LEO loiter to check the fuel cell function and provide power for 90 minutes of crew access to the vehicle. During this short period, the Altair fuel cells provide power for Altair's entire load and power transfer from EDS is not required. At LOI-24 hours Altair fuel cells power up and Altair remains on internal power for the remainder of its mission with zero power transfer from other elements required. The surface stay is powered by fuel cells for 7 days for a Sortie lander and 24 hours for an Outpost lander. It is assumed that outpost landers would be connected to an LSS power source within 24 hours of landing to maintain vehicle systems until ascent. After lunar touchdown, the propellant residuals must be prepared for scavenging. An initial assumption of 3 hours was used in this analysis. At touchdown +3 hours the fuel cells are supplied using scavenged propellant. Batteries power the Ascent Module from minutes prior to ascent through disposal.

Cargo landers operate on internal power for their entire mission with no power transfer from other elements. Cargo landers remain powered for 24 hours after landing on the lunar surface. As for the outpost mission, it is assumed that this provides enough time to connect the lander to an LSS power resource if necessary for payload support.

LSS consists of the lunar outpost and all associated equipment (rovers, etc). The method of power transfer to the lander is undefined at this point though several options are being considered.

\section{Thermal}

Altair systems use fuel cell product water whenever possible. The thermal system sublimators are the largest consumer of this water prior to lunar landing. When predicted fuel cell water is not sufficient to satisfy mission needs, additional water will be loaded into the thermal water tank prior to Earth launch. This water pre-load is limited to the minimum amount required to complete the mission and varies with each DRM. 


\section{Life Support}

Life support consumables (oxygen, nitrogen, water) are provided by Orion while the vehicles are docked. Oxygen tanks on the AM supply oxygen for lunar descent, the first three hours of the surface mission, and ascent. Three hours after lunar touchdown oxygen is acquired through propellant scavenging. Water is continually produced by the fuel cells when Altair switches to internal power prior to LOI and is stored in the thermal and potable water tanks.

4. Propellant Scavenging \& LSS

To minimize the fuel cell reactants and life support oxygen that must be pre-loaded onto Altair, descent module main propellant residuals are scavenged after touchdown on the lunar surface. After landing, three hours are allowed for reconfiguring systems and purging helium pressurant gas from the oxygen tanks before scavenging can begin. This initial assumption of 3 hours must be refined by analysis and testing. While on the surface, the fuel cells produce water faster than it is used and eventually, the water supply exceeds the storage capacity. No allocation of water is assumed for cleaning EVA equipment: this is one potential use of excess water. If excess water remains after all cleaning needs are satisfied, one likely solution is to capture this excess water in portable containers and transport it to the lunar outpost if present. This solution is not yet supported in the current Altair design. Vent valves can be used to prevent the tanks from over-filling.

Additional propellant scavenging after the ascent module and crew depart has been studied as a way to provide more consumables to a lunar base. However, any additional hardware or operational capability to support post ascent scavenging is not supported in the current lander design.

\section{B. Risk Reduction}

The Altair design team follows a risk informed design approach. ${ }^{7}$ The first design cycle, DAC-1, focused on the development of a minimally functional vehicle. The second and third design cycles focused identification and mitigation of loss of crew (LOC) risks and loss of mission (LOM) risks. Risk reduction in the thermal system is a driving factor in the quantity of water that is maintained and the maximum tank capacities for both the thermal and potable water tanks. To minimize risk of LOC during descent Altair must be able to abort the descent in the event of a failure, jettison the DM and return the crew to Orion using the AM. If an abort is called, water system redundancy can further reduce the risk of LOC. For this reason, the water contained in the thermal and potable water tanks must be sufficient to accomplish thermal control for the descent and for twice the amount that would be required if the descent were aborted. Similarly during a nominal ascent some redundancy is in place to reduce the risk of LOC and LOM. While the time to ascend and rendezvous with Orion can take $2-3$ times longer in an abort situation, the total water and power consumption remains close to the same. This is achieved by powering down all non-critical Altair systems when an abort is called, reducing the amount of water required for cooling and prolonging the life of the AM batteries. Water requirements for the Sortie mission are given in Table 1.

Table 1. Water Requirements.

Water consumed during a lunar ascent from an aborted descent $\quad 22 \mathrm{~kg}$

Water consumed for a nominal ascent $\quad 25 \mathrm{~kg}$

Water consumed for an aborted ascent $\quad 35 \mathrm{~kg}$

Water required to be present on Altair just prior to lunar touchdown $\quad 44 \mathrm{~kg}$

Water required to be present on Altair just prior to lunar ascent $\quad 50 \mathrm{~kg}$

\section{Analysis}

Analysis of the water balance over the mission is needed to ensure thermal and life support needs are adequately met. While a significant quantity of water is produced by the fuel cells, it does not completely satisfy the mission needs. There are two critical gates where water quantity must be at or above a certain level. These are just prior to lunar descent and just prior to lunar ascent, see Table 1.

Figure 4 shows the total quantity of water available on Altair throughout the mission, beginning at Earth launch and ending at undocking from Orion after crew have returned from their lunar stay. Figure 5 and Table 2 show the individual contributors to the water level. The major mission events, TLI, LOI, Lunar Descent \& Lunar Ascent are marked. The quantity in Figure 4 remains relatively constant for the first 8 days, with the slight increase occurring as the fuel cells are checked out in LEO, which produces some small quantity of water. The level increases rapidly when the fuel cells are turned on again 24 hours prior to LOI. The slope of the increase in water level decreases between LOI and Lunar Descent because in LLO the thermal system is consuming water to supplement the radiators which are not fully able to reject Altair's heat load in this environment. 


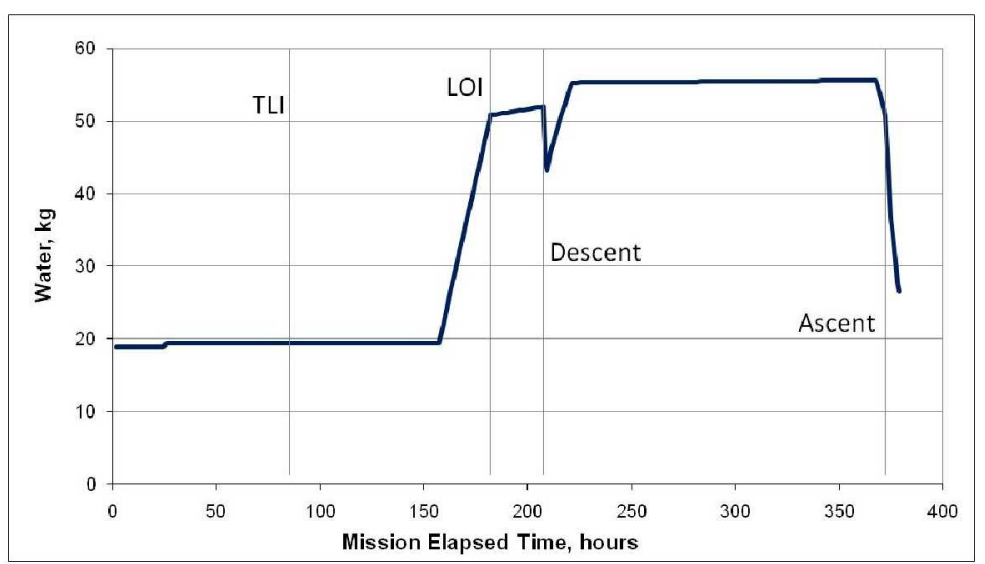

Figure 4. Altair Water Level.

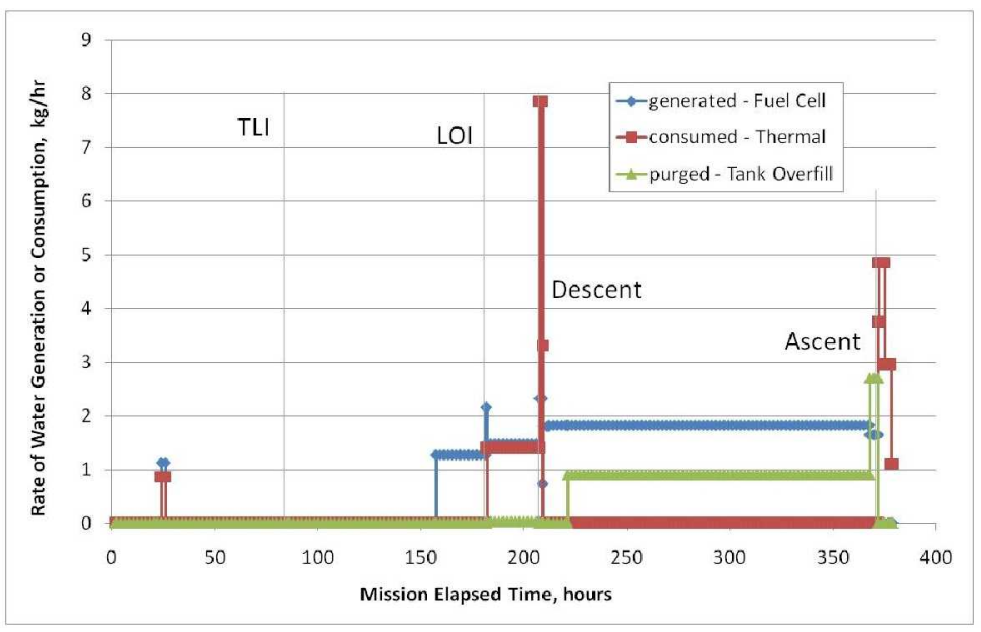

Figure 5. Altair Water Generation and Consumption Rates.

The rate of water consumption increases during descent resulting in a decline in total water. Just prior to lunar touchdown, there must be at least $22 \mathrm{~kg}$ of water in each of the two water tanks to support a possible aborted descent with redundancy. To meet this requirement the tanks must be partially filled, or pre-loaded, on Earth.

Once on the lunar surface, the thermal system no longer consumes water, and crew consumption is very small. The quantity of water on the vehicle rises until it meets the capacity of the two water tanks. When capacity is reached, additional water generated must be vented overboard or extracted for transfer to a lunar base.

In preparation for ascent, excess water is vented overboard to match the $50 \mathrm{~kg}$ quantity needed for robust ascent capability. At the conclusion of a nominal ascent, $25 \mathrm{~kg}$ of water remains on the vehicle.

One of the critical components of Altair's water and power supply is the ability to scavenge residual propellants from the descent module after lunar touchdown. Figure 6 shows the propellant quantities available over the course of the mission. Three percent of the maximum propellant loading is reserved for residual propellant that will remain in the tanks after engine shutdown. It is assumed that all other propellant margins are consumed during descent. In Figure 7 one can see that $706 \mathrm{~kg}$ of Oxygen and $130 \mathrm{~kg}$ of Hydrogen remain in the tanks. These residual propellants are then scavenged to supply the fuel cells and crew systems. At the conclusion of the nominal Polar Sortie mission, there is still a significant quantity of propellant remaining in the tanks, $398 \mathrm{~kg}$ Oxygen, $97 \mathrm{~kg}$ Hydrogen. This analysis assumes no propellant loss due to venting or excess boil off. It is expected that some quantity of oxygen would be lost when helium is vented from the system. It is also expected that the boil off rate for hydrogen will exceed the demand rate from the fuel cell, leading to periodic venting of the tank and loss of hydrogen for pressure control.

Table 2. Other Water Consumption Rates While on the Lunar Surface

$\begin{array}{rrc}\text { Crew Potable (Drinking and Food Preparation) } & 2.5 & \mathrm{~kg} / \mathrm{person} / \mathrm{day} \\ \text { Crew Hygiene } & 0.4 & \mathrm{~kg} / \mathrm{person} / \mathrm{day} \\ \text { Crew Drinking During EVAs } & 3 & \mathrm{~kg} / \mathrm{person} / 8 \text {-hr EVA } \\ \text { Suit Thermal Control during EVAs } & 1.8 & \mathrm{~kg} / \mathrm{person} / 8-\mathrm{hr} \text { EVA }\end{array}$




\section{Possible Resources Available for LSS}

As plans for a lunar outpost mature it is clear that water will be a critical resource. While water for crew consumption is an obvious necessity, there are other aspects of an outpost design where water is particularly beneficial. Because of its high hydrogen content, water can act as an efficient radiation shield. Some outpost concepts include water walls to protect crew sleeping quarters. These concepts can use $1,000 \mathrm{~kg}$ of water for this purpose. ${ }^{8}$ Water can also become a means of storing energy. Due to frequent days-long shadowing of the Sun, a photovoltaic array and Regenerative Fuel Cell (RFC) power station may be the only viable non-nuclear option for long-term reliable energy production at South Pole landing sites. The fuel cells produce power and water from hydrogen and oxygen reactants when the Sun is eclipsed, then when the Sun is visible the solar array provides power for electrolysis which is used to convert the water back into its hydrogen and oxygen components to complete the repeating cycle. For these reasons, it is highly desired to extract excess water and its components from all of the Altair landers that visit the outpost location. While a method of extraction has not been thoroughly studied, estimates for the potential quantities of resources that might be extracted are given in Table 3. These values are based on the analytical and experimental work in Reference 5. The assumption for propellant residual mass is a

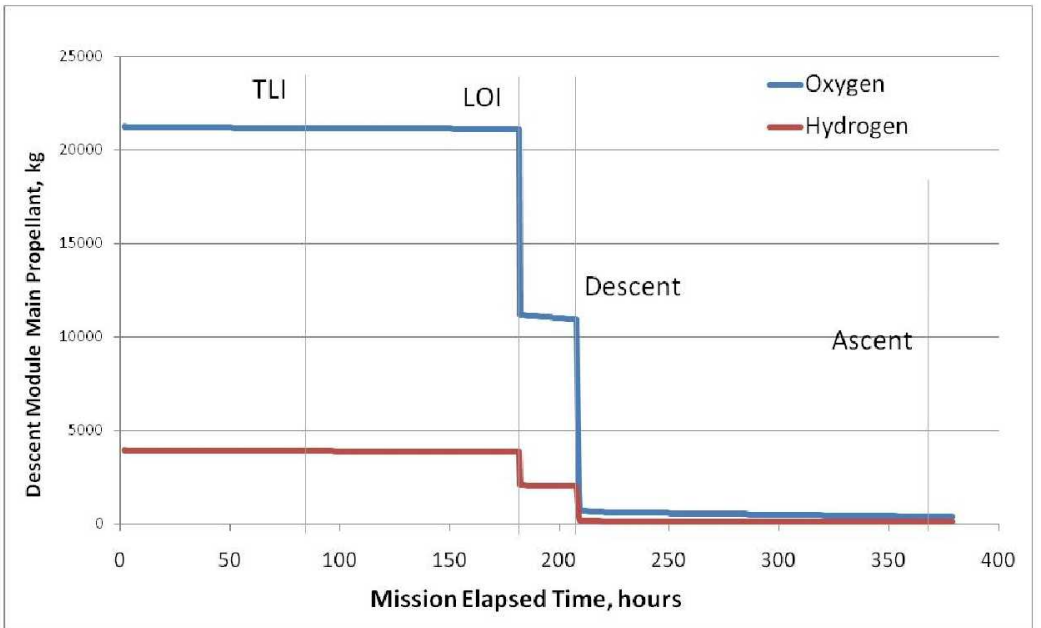

Figure 6. Altair Descent Module Main Propellants.

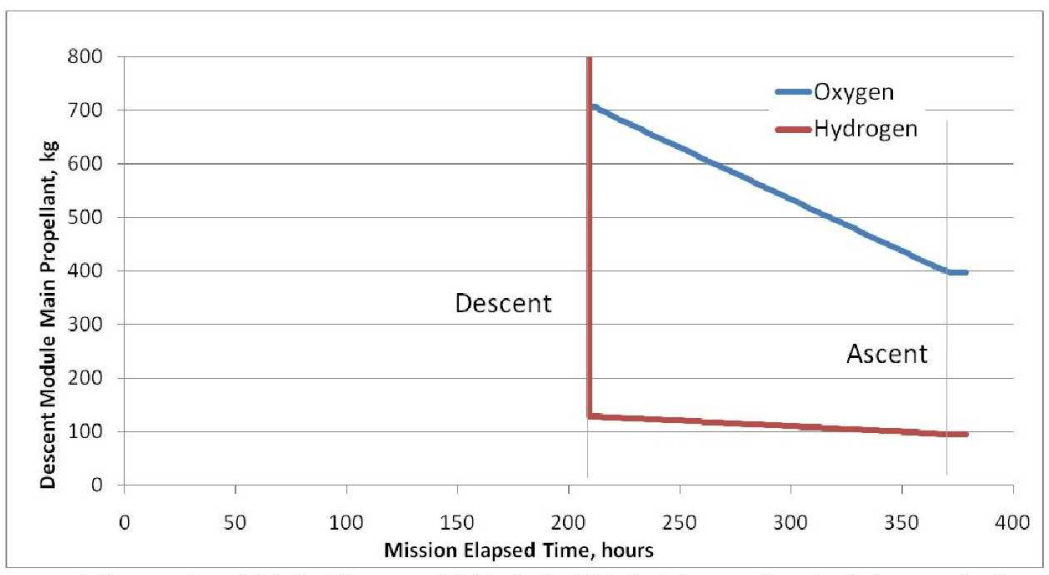

Figure 7. Altair Descent Module Main Propellants (Expanded View).

little higher than was found in the final DAC-3 analysis, but even accounting for the slight discrepancy one can see that a significant amount of water could be made available to LSS. Altair Outpost and Cargo missions would have a greater quantity of resources available for LSS since the duration the lander must consume those resources would be much shorter, possibly 1 day rather than 7. If the Altair fuel cells are used to convert the excess residuals into water for LSS, a significant amount of energy can be produced. Some of the energy in Table 3 would have to be used to power fuel cell ancillaries, but some power could be extracted for LSS use.

Table 3. Potential Water Available to LSS.

\begin{tabular}{|c|c|c|c|c|c|}
\hline & & Oxygen & Hydrogen & Water & Energy \\
\hline \multicolumn{6}{|l|}{ SORTIE } \\
\hline Liquid and Gaseous Residual Propellant at Engine Shutdown & $(\mathrm{kg})$ & 752 & 216 & & \\
\hline Residual Propellant After Nominal Lander Mission* & $(\mathrm{kg})$ & 469 & 147 & & \\
\hline Estimated 'Trapped' Gases at final temperature & $(\mathrm{kg})$ & 80 & 20 & & \\
\hline Extractable Propellant Residuals for LSS & $(\mathrm{kg})$ & 389 & 127 & & \\
\hline Equivalent Water if Processed with Fuel Cells & $(\mathrm{kg})$ & 0 & 78 & 438 & \\
\hline Energy Generated Through Water Processing & $(\mathrm{kW}$-hrs $)$ & & & & 963 \\
\hline Additional Water (Excess During Surface Mission) & $(\mathrm{kg})$ & & & 86 & \\
\hline Total Potential Water to LSS & $(\mathrm{kg})$ & & & 523 & \\
\hline
\end{tabular}

*Takes into account both venting losses and Altair use 


\section{E. Benefits of Resource Reuse}

Without propellant scavenging, Altair's 7-day surface mission would require an additional $342 \mathrm{~kg}$ of hydrogen and oxygen consumables for the fuel cells and crew plus additional mass for storage tanks. Without scavenging, building the lunar outpost could require many hundreds more kilograms of resources delivered to the surface. Payload capability would be significantly reduced on each lander, and a greater number of lander missions would be required to build a lunar outpost.

The Altair polar Sortie mission requires $247 \mathrm{~kg}$ of water from Earth launch through end of mission. Fuel cells currently provide water during transit to the moon and excess water while on the lunar surface. If fuel cells were not chosen for the Altair power system, the required water would have to be carried from Earth in larger water tanks to support the thermal and crew needs.

\section{Conclusion}

In the current Altair design the same Hydrogen and Oxygen atoms can serve 3 functions: they act as necessary residuals in the propellant tanks ensuring only high quality propellants are expended during descent, once on the surface they are then used to generate power for the lander, and they are consumed by the crew in the form of water and oxygen. Reusing lander resources with several subsystems allows more payload to be brought to the surface and may help to build lunar outpost resources.

\section{Acknowledgments}

The authors would like to thank Bob Klimek for assistance with consumables analysis and Ryan Stephan and Molly Anderson for thermal and life support expertise.

\section{References}

\footnotetext{
1 “Constellation Design Reference Missions and Operational Concepts", CxP 70007, Revision B, Change 002, June 19, 2008

${ }^{2}$ Campos, Arturo B., "Apollo Experience Report - Lunar Module Electrical Power Subsystem”, NASA Technical Note TN D-6977, September 1972.

${ }^{3}$ Trout, J. Barry, “Apollo Experience Report - Battery Subsystem”, NASA Technical Note TN D-6976, September 1972.

4 Steigerwald, Bill, "Treasure Hunting on the Moon: Lunar Reconnaissance Orbiter and the Search for Water", http://www.nasa.gov/mission_pages/LRO/news/water_search.html, October 2008.

${ }^{5}$ Linne, D., Plachta, D., Chato, D., Sutherlin, S., Notardonato, W., Salerno, L,. "Feasibility of Scavenging Propellants from Lander Descent Stage to Supply Fuel Cells and Life Support", AIAA-2009-6511, SPACE 2009 Conference and Exposition, September 14-17, 2009

${ }^{6}$ Brady, J.C.; Browne, D.M.; Schneider, H.J.; and Sheehan, J.F.: Apollo Lunar Module Environmental Control System Mission Performance and Experience. ASME Paper No. 73-ENA-28, American Society of Mechanical Engineers (New York), 1973.

${ }^{7}$ Lenius, J., Jones, B., "Returning to the Moon Via a Risk Informed Design", Third IAASS Conference, Rome, October 2123,2008

${ }^{8}$ Toups, L., Kennedy, K., et al., "Constellation Architecture Team - Lunar Habitation Concepts", AIAA-2008-7633, SPACE 2008 Conference and Exposition, September 9-11, 2008
} 